\title{
Hand eczema and patch testing - A clinico-allergiological study
}

\section{Mrinal Gupta}

\author{
Department of Dermatology, Treatwell Skin Centre, Jammu and Kashmir, India
}

Corresponding author: Dr. Mrinal Gupta, E-mail: drmrinalgupta@yahoo.com

\begin{abstract}
Background: Hand eczema is a common and distressing condition. Most of the cases of hand eczema have a multifactorial etiology. Most of the cases of hand eczema are irritant contact dermatitis due to irritants like soaps and detergents, but a large number of cases occur due to contact allergy to specific substances. Patch testing is an important diagnostic tool for identification of the probable allergens responsible for the eczema. Objectives: The aim of this study was to study the patterns of hand eczema and to identify the most common allergens causing dermatitis using patch testing. Patients and methods: Thirty consecutive patients (M: F=11: 19) with hand eczema were examined, detailed history was taken, and the pattern of dermatitis was noted. All of them were subjected to patch testing using the Indian Standard Series. Results: The study included 11 (36.67\%) men aged between 23 and 54 years and 19 (63.33\%) women aged between 28 and 49 years. The majority of patients were in the $21-50$ years age group $(86.67 \%$; $n=26)$. The most common occupational group among females was housewives $(63.15 \%, \mathrm{n}=12)$ while among the males the most common occupational group was farm workers $(54.54 \%, \mathrm{n}=6)$. Discoid eczema was the commonest morphological pattern seen in $36.67 \%(\mathrm{n}=1 \mathrm{l})$ of cases, followed by hyperkeratotic eczema in 30\% $(\mathrm{n}=9)$. On performing a patch test, $21(70 \%)$ patients showed positive reaction to one or more allergens. In our study, positivity through patch test was found to be highest for nickel (33.33\%), followed by potassium dichromate (28.57\%), paraphenylenediamine, parthenium, fragrance mix and cobalt chloride. Potassium dichromate was the most common allergen in males while among females, nickel was the predominant allergen. Conclusions: Hand eczema is a common problem predominantly seen in females in the middle age groups. It can be both due to exposure to irritants and due to development of contact sensitivity to various allergens with nickel and chromates being the most commonly implicated agents.
\end{abstract}

Key words: Eczema; Contact dermatitis; Hand eczema; Occupational dermatoses; Paraphenylenediamine

\section{INTRODUCTION}

Hand eczema is a chronic and distressing condition with a point prevalence of $1-5 \%$ among adults in the general population. Hand eczema is twice as common in women as in men and is more common among people with some kind of occupational exposure [1]. Hand eczema may be endogenous or exogenous in origin and most of the cases of hand eczema have a multifactorial etiology. Endogenous causes of hand eczema are atopic dermatitis, discoid eczema, hyperkeratotic eczema and pompholyx. The most common external cause of hand eczema is contact with irritant or mild toxic agents like soaps or detergents. Allergic contact dermatitis of hands is much less common than irritant and occurs only in people who have developed a contact allergy to specific substance such as rubber chemical, nickel or other allergens [2,3]. As clinical differentiation between chronic allergic and irritant hand eczemas is often impossible, patch testing becomes an important diagnostic tool for identification of the probable allergens responsible for the eczema.

The aim of this study was to study the patterns of hand eczema and to identify the most common allergens causing dermatitis using patch testing. 


\section{MATERIALS AND METHODS}

Thirty consecutive patients with hand eczema were included in the study after taking an informedconsent. Pregnant or lactating women were excluded.Patients having acute dermatitis were patch testedafter control of their dermatitis, when they were offsystemic corticosteroids, or the dose of prednisolonewas less than $20 \mathrm{mg} /$ day. Details about age, sex,personal or family history of atopy (nasobronchialallergy, asthma, and childhood eczema), use of various products and its duration, onset, duration, anddistribution of dermatitis were noted. The enrolledpatients were patch tested by using the Finnchambers method with the Indian Standard Seriesrecommended by the Contact Dermatitis andOccupational Dermatoses Forum of India (Table 1). Patches were applied on the upper back and thepatients were asked to return for results after $48 \mathrm{~h}$ (day 2) and $72 \mathrm{~h}$ (day 3). The results were gradedaccording to the International Contact DermatitisResearch Group criteria [4]. Only reactionspersisting on day 3 were considered positive for thefinal analysis. Relevance of a positive patch test resultswas determined clinically.

Side effects such as adhesive tape reaction, discomfortand itching, flare of dermatitis, angry back phenomenon, active sensitization, and pigment alteration at test site, when they occurred, were recorded. A patch test for thesuspected cosmetic agent itself and the photopatch testwere not carried out.

\section{RESULTS}

The study included $11(36.67 \%)$ men aged between 23 and 54 years and $19(63.33 \%)$ women aged between 28 and 49 years. The majority of patients were in the $21-50$ years age group $(86.67 \% ; n=26)$. The totalduration of dermatitis was less than 1 year in $21(70 \%)$ patients, $1-5$ years in six $(20 \%)$ patients, and more than 5 years in three $(10 \%)$ patients. The minimum duration was 1 month andthe maximum duration was 6 years, and the mean duration was 19 months. Eight (26.67\%) patients had a history of atopy. The most common occupational group among females was housewives $(63.15 \%, \mathrm{n}=12)$ followed by students $(21.05 \%, \mathrm{n}=4)$ while among the males the most common occupational group was farm workers $(54.54 \%, \mathrm{n}=6)$, followed by office workers $(27.27 \%$,
Table 1: Etiological profile of various allergens among patients

\begin{tabular}{lccc}
\hline Allergens & \multicolumn{3}{c}{ Number (\%) } \\
\cline { 2 - 4 } & Male & Female & Total \\
\hline 1/Vaseline & - & - & - \\
2/Black rubber Mix & - & - & - \\
3/Potassium dichromate & $5(45.45)$ & $1(9.09)$ & $6(28.57)$ \\
4/Colophony & - & $1(5.26)$ & $1(4.76)$ \\
5/Formaldehyde & - & - & - \\
6/Nickel sulphate & $1(9.09)$ & $6(31.57)$ & $7(33.33)$ \\
7/Cobalt chloride & $1(9.09)$ & $1(5.26)$ & $2(9.52)$ \\
8/Mercaptobenzothiazole & - & - & - \\
9/Fragrance mix & - & $2(10.52)$ & $2(9.52)$ \\
10/Balsam of peru & - & - & - \\
11/Paraphenylenediamine & $1(9.09)$ & $2(10.52)$ & $3(14.29)$ \\
12/Epoxy resin & - & - & - \\
13/Thiuram mix & - & - & - \\
14/Neomycin sulphate & - & - & - \\
15/Benzocaine & - & - & - \\
16/Nitrofurazone & - & - & - \\
17/Parthenium & $1(9.09)$ & $1(5.26)$ & $2(9.52)$ \\
18/Chlorocresol & - & - & - \\
19/Wool alcohol & - & - & - \\
20/Parabens mix & - & - & - \\
Total & 9 & 14 & 23 \\
\hline
\end{tabular}

$\mathrm{n}=3)$. The disease was bilateral in $86.67 \%$ patients $(n=26)$. Palms were involved in $46.67 \%(n=14)$ patients, fingers in $30 \%(n=9)$ patients, dorsa of hands in $16.67 \%(\mathrm{n}=5)$ patients and whole hand in $6.67 \%(\mathrm{n}=2)$ patients. Scaling was the most common presentation seen in $70 \%(\mathrm{n}=21)$ patients followed by erythema, fissuring, hyperpigmentation, papules, papulovesicles, vesicles and oozing. Discoid eczema was the commonest morphological pattern seen in $36.67 \%(n=11)$ of cases, followed by hyperkeratotic eczema in $30 \%(n=9)$, palmar and vesicular palmar eczema in 13.335 each $(n=4)$ and fingertip eczema in $6.67 \%(n=2)$ cases.

On performing a patch test, $21(70 \%)$ patientsshowed positive reaction to one or more allergens, thus confirming the diagnosis of allergic contact dermatitis. Eighteen patients showed patch test positivity to one allergen while the remaining patients had sensitivity to two or more allergens on patch testing. The etiological allergens in the study population are described in Table 1. Potassium dichromate was the most common allergen in males while among females, nickel was the predominant allergen.

\section{DISCUSSION}

Hand eczema is one of the most common dermatological disorders encountered in dermatological practice. 
Irritants and contact allergens are the major etiological agents in hand eczema and they frequently co-exist. In most of the cases it is not possible to identify the cause as irritant or allergic. So, patch testing becomes an important diagnostic tool for identification of the allergen or allergens responsible for eczema $[5,6]$.

Hand eczema affects both the sexes but is predominant among the females as reported in various studies [7]. Our study included 11 (36.67\%) men aged between 23 and 54 years and $19(63.33 \%)$ women aged between 28 and 49 years. This is probably due to increased exposure of females to wet work, soaps and detergents while washing and to vegetables while cutting and cooking. Occupation has significant bearing on hand eczema because of exposure to various allergens at workplace. The most common occupational group among females was housewives $(63.15 \%, \mathrm{n}=12)$ while among the males the most common occupational group was farm workers $(54.54 \%, \mathrm{n}=6)$. This observation is in agreement with the study conducted on hand eczema by Kishore et al who also found housewives to be the most common occupational group in females and skilled and semiskilled workers among males [8]. There are several types of hand eczema with a distinctive appearance of which the cause is unknown.Discoid eczema was the commonest morphological pattern seen in our study, followed by hyperkeratotic eczema palmar and vesicular palmar eczema. Laxmisha et al, studied 36 cases of hand eczema and found fissuring in 19 cases, hyperkeratotic type in 4 cases, vesicular type in 3 cases, and pompholyx in 1 case [5].

The gold standard for diagnosing allergic contact dermatitis, a type IV delayed hypersensitivity reaction, is patch testing. The basis of the testing is to elicit an immune response by challenging already sensitised persons to defined amounts of allergen and assessing the degree of response. Patch test positivity in the present study was found to be $70 \%$ to one or more allergens. Patch test positivity in various studies on hand eczema has been found to vary from 46-82\% [5-9]. In our study, positivity through patch test was found to be highest for nickel (33.33\%), followed by potassium dichromate (28.57\%), paraphenylenediamine, parthenium, fragrance mix and cobalt chloride. In males, potassium dichromate turned out to be most common allergen with $45.45 \%$ cases while in females the most common allergen was nickel sulphate with $31.57 \%$ cases. This is comparable to a study by Kishore et al, where potassium dichromate was the commonest sensitizer testing positive in $26 \%$ of patients while nickel was the next common allergen testing positive in $18 \%$ of the patients [8].

Chromates are present in cements, leather, matches, bleaches, yellow paints, varnishes.Western countries have reported a sharp decline in chromate positivity since the introduction of ferrous sulphate in cement, which converts the easily absorbable hexavalent chromium to the less sensitizing trivalent form. In the present study, potassium dichromate was found to be the commonest allergen positive in masons and labourers. The results of our series are in league with the study conducted by Laxmisha et al in which potassium dichromate was the most common allergen [8]. Patients in our study had significant occupational exposure to chromates, thereby increasing the risk of contact sensitivity to chromates, which could explain the high number of positive patch test reactions to potassium dichromate noted by us.Positive reactions to chromate in metal workers and construction workers was also observed by $\mathrm{Ni}$ et al in their study of hand eczema [10]. Nickel is another common sensitizer, perhaps due to its widespread use in imitation jewellery, watches, buttons, zippers, rings, doorknobs, batteries, metal-cutting fluids, coins, orthopaedic plates, keys, spectacle frames and kitchenware [8]. Systemic exposure can take place from diet. The commonest clinical presentation of hand eczema induced by ingested nickel is 'dyshidrotic,' vesicular eczema. Women are more commonly affected and have an earlier age of onset than men [11]. In our study nickel sulphate turned out to be the most common sensitizer in women while no men were found to be sensitive to this metal.

\section{Limitations}

Hand eczema can occur due to awide variety of chemicals other thanthose available in the Standard Series, which could have led to contact dermatitis. Unavailability ofthese allergens, unavailability of the photopatch testing, the small number of patients and not testing withpatients' own cosmetics may have resulted in our missing some cases of contact dermatitis.

\section{CONCLUSIONS}

Hand eczema is a common problem predominantly seen in females in the middle age groups. It can be both due to exposure to irritants and due to development of contact sensitivity to various allergens present in different substances with nickel and chromates being 
the most commonly implicated agents. Patch test is an important tool in determining the causative allergens, which will be of help to the patients to avoid the allergens and better management of the disease.

\section{REFERENCES}

1. Coenraads PJ. Hand eczema is common and multifactorial. J Invest Dermatol. 2007;127:1568-70.

2. Suman M, Reddy BS. Pattern of contact sensitivity in Indian patients with hand eczema. J Dermatol. 2003;30:649-54.

3. Mahajan BB, Kaur S. Impact of hand eczema severity on quality of life: a hospital based cross-sectional study. Our Dermatol Online. 2016;7:1-4.

4. Wilkinson DS, Fregert OS, Magnusson B, Bandmann HJ, Calnan CD, Cronin E, et al. Terminology of contact dermatitis. Acta DermVenereol. 1970;50:287-92.

5. Laxmisha C, Kumar S, Nath AK, Thappa DM. Patch testing in hand eczema at a tertiary care centre. Indian J Dermatol VenereolLeprol. 2008;74:498-9.

6. Parajuli S, Paudel V, Paudel U, Pokhrel DB. Pattern of patch test reactivity among patients with clinical diagnosis of contact dermatitis: A hospital-based study. Our Dermatol Online. 2017;8:389-92.

7. Kishore NB, Belliappa AD, Shetty NJ, Sukumar D, Ravi S. Hand eczema-Clinical patterns and role of patch testing. Indian J Dermatol Venereol Leprol. 2005;71:207-8.

8. Toledo F, García-Bravo B, Fernández-Redondo V, De la Cuadra J, Giménez-Arnau AM, Borrego L, et al. Patch testing in children with hand eczema. A 5-year multicentre study in Spain. Contact Dermatitis. 2011;65:213-9.

9. Ni C, Dou X, Chen J, Zhu X, Liu L. Contact sensitization in Chinese patients with hand eczema. Dermatitis. 2011;22:211-5.

10. Jindal R, Sharma NL, Mahajan VK, Tegta GR. Contact sensitization in venous eczema: Preliminary results of patch testing with Indian standard series and topical medicaments. Indian J Dermatol VenereolLeprol. 2009;75:136-41

Copyright by Mrinal Gupta. This is an open-access article distributed under the terms of the Creative Commons Attribution License, which permits unrestricted use, distribution, and reproduction in any medium, provided the original author and source are credited.

Source of Support: Nil, Conflict of Interest: None declared. 